\title{
Mechanical Properties of Sandstone Roof and Surrounding-Rock Control of Mining Roadways Subject to Reservoir Water Disturbance
}

\author{
Bin Ma, ${ }^{1}$ Zaiqiang Hu $\left(D,{ }^{1}\right.$ Xingzhou Chen $\left(D,{ }^{2}\right.$ Lili Chen, ${ }^{2}$ and Wei Du ${ }^{2}$ \\ ${ }^{1}$ School of Civil Engineering and Architecture, Xi'an University of Technology, Xi'an 710077, China \\ ${ }^{2}$ School of Architecture Civil and Engineering, Xi'an University of Science and Technology, Xi'an 710054, China \\ Correspondence should be addressed to Zaiqiang Hu; huzq@xaut.edu.cn
}

Received 14 December 2020; Revised 20 January 2021; Accepted 28 January 2021; Published 13 February 2021

Academic Editor: Faming Huang

Copyright (C) 2021 Bin Ma et al. This is an open access article distributed under the Creative Commons Attribution License, which permits unrestricted use, distribution, and reproduction in any medium, provided the original work is properly cited.

\begin{abstract}
Sandstone-roofed roadways are susceptible to deformation and failure caused by reservoir-water-induced disturbances, thereby compromising human safety. Using rock-mechanics testing techniques, numerical simulations, and engineering principles, this study investigates the strength, deformation, and pore-structure characteristics of sandstone roofs as well as means to support the surrounding rock structure. The results obtained in this study reveal that the residual strain is proportional to the pore-water pressure, which, in turn, causes a significant reduction in the elastic modulus during the unloading phase. Furthermore, an increase in the pore-water pressure causes the shear failure of specimens in compression. The delay between crack initiation and specimen-volume expansion decreases. Moreover, the specimen demonstrates increased deformation and failure responses to changes in the confining pressure, thereby resulting in accelerated conversion. Changes in water inflow can be correlated to crack initiation, propagation, and fracture. This water inflow gradually increases with an increase in the osmotic pressure. Correspondingly, the volumetric strain required for maximum water inflow undergoes a gradual decrease. The increased water inflow can be considered a precursor to specimen failure. In addition, fractures in the surrounding rock structures are mainly caused by joint dislocations. The increase in pore pressure promotes the development of dislocation fractures in the deep surrounding rocks. Subsequently, these fractures overlap with their open counterparts to form large fractures; this increases the roadway-roof subsidence and layer separation of the shallow surrounding rocks, thereby further increasing the fracture count. Lastly, the use of high-performance rock bolts, cable-bolt reinforcements, and W-shaped steel bands is expected to ensure the stability of rocks surrounding sandstone-roofed roadways subject to water-pressure disturbances.
\end{abstract}

\section{Introduction}

The rapid development of mining technologies has resulted in an increased mineral-resource demand in China. However, these mineral resources, being nonrenewable, are prone to depletion $[1,2]$. Therefore, the research on mining of resources that require complicated extraction process, especially those found under water bodies, such as reservoirs and rivers, has attracted significant attention in recent times [3]. Mining activities destroy existing rock-stress fields, thereby causing movement of the overlying strata and promoting the infiltration of surface water and water in aquifers into the ground. In particular, surface water bodies-the main supplemental sources of mine water- significantly affect the safety of underground production activities. Therefore, the safe extraction of minerals from under water bodies is an important research topic from the rock-mechanics and engineering viewpoints.

Sun et al. [4] studied the overburden-failure process under reservoir mining conditions by performing physical and numerical simulations. They deduced the relationship between the maximum height of the water-conducting fissure development and coal-seam mining thickness. Dyke et al. [5] studied the relationship between rock strength and its sensitivity to water content. They revealed that a decrease in moisture content suppresses the onset of dilatancy and 
microcracking. Colback et al. [6] analyzed the relationship between the compressive strength of South African quartzite and changes in water content. Subsequently, they discussed the quantitative effects of moisture on the compressive strength of rocks. Hadizadeh [7] analyzed the softening effect of water on sandstone. Risnes et al. [8] investigated the weakening and damaging effects of water on the microstructures of cretaceous rocks; they reported the waterweakening effect to be considerably reduced in high-ionicstrength solutions. Yao [9] investigated the physical and mechanical properties of water-enriched sandstones. They suggested the basic principle underlying the weakening of water-rich roadway roofs. Zhu et al. [10] analyzed the internal mechanisms related to the impact of water on the characteristic strength of saturated marble. They postulated that the mechanism influencing the fracture-initiation strength after rock-sample saturation is due mainly to the pore-water pressure and the "hindering force" of crack propagation. Zhu et al. [11] analyzed the influence of water pressure inside cracks on the compressive strength of rock masses. Moreover, they deduced equations to evaluate the initial rupture strength of rocks subjected to hydraulic pressures. Chen et al. [12] discussed macromechanisms underlying the changes in interactions between the water pressure and confining pressure on rocks. They revealed cases involving hydraulic unloading to demonstrate a significant impact on rock strength compared to those without hydraulic unloading. Tang et al. [13] analyzed the evolution patterns of the volume-expansion characteristics of sandstones with different moisture content. They reported that an increase in moisture content decreases the closure stress, initiation strength, damage strength, and peak strength of sandstone. Deng et al. [14, 15] investigated the effects of different pore-water pressures on the unloading deformation and failure characteristics of sandstone. They observed the lateral-expansion phenomenon to become obvious under high and low pore water and confining pressures, respectively. Xu et al. [16] performed pore-water pressures tests on saturated sandstones subjected to cyclic loading and unloading under constant triaxial confining-pressure settings. They reported the relationship between the residual strain and cyclic numbers to agree with the power of negative index under cyclic loading and unloading pore-water pressures. Wang et al. [17] experimentally studied the evolution characteristics of sandstone permeability based on the unloading path. They reported sandstone to sustain brittle failure and its lateral deformation and volume to expand significantly upon an increase in the initial confining pressure or unloading rate. Wang et al. [18] performed permeability tests on gritstones during deformation and failure under different confining-pressure conditions. They identified gritstone permeability as more sensitive to hoopstrain changes during rock-sample deformation and failure. Zhu et al. [19] studied the safety of coal mining under barrier lakes. They observed the coal-seam bedrock thickness to exceed the required dimensions of the safety waterproof pillar.

Most extant studies investigate the weakening of the physical properties of sandstone under the action water as well as the overburden-failure characteristics of underwater mining activities. However, studies concerning the stability and control of roadway-roof mining under water-pressure disturbances are seldom undertaken. Underwater miningroadway activities are classified as water-rock interactions. The mechanical properties of rocks surrounding these roadways inevitably deteriorate. Moreover, hydrophilic minerals in these surrounding rocks tend to swell and deform after water absorption, thereby adversely affecting the operational safety and maintenance of such roadways. For these reasons, the underwater mining roadway is considered in this study to perform engineering evaluations. This study analyzes the weakening trends and strength characteristics of sandstone roofs above roadways subjected to reservoir water disturbances. The corresponding results obtained were interpreted via unloading seepage tests, numerical simulations, and engineering assessments to determine the theoretical basis and practical significance of mining safety while considering reservoir water disturbances.

\section{Experimental Preparation}

2.1. Experimental System and Sample Preparation. The thermal-hydrological-mechanical-chemical (THMC) multifield coupling triaxial rheological testing system for rocks (Figure 1) was used in this study for the evaluations. The equipment is capable of automatically collecting data for changes in force and displacement during the loading process. The system working pressures were as follows: confining pressure of $0-100 \mathrm{MPa}$, axial pressure of $0-1500 \mathrm{kN}$, and osmotic working pressure of $0-60 \mathrm{MPa}$. A standard pressure/volume controller was used to collect the fluid from the upstream extremity.

The specimens used as the experimental materials were obtained from the sandstone roof of a coal mine roadway under a reservoir in the western part of China. According to the requirements of rock testing based on the relevant test standards and specifications, the YRD-2 CNC core cutting machine was used to prepare cylindrical specimens $(\varphi 50 \mathrm{~mm} \times L 100 \mathrm{~mm})$, with the roughness at both ends of the specimens controlled within $\pm 5 \mathrm{~mm}$. The prepared samples are shown in Figure 2.

\subsection{Experimental Methodology.}

(1) The obtained specimens were dried in an oven at $105^{\circ} \mathrm{C}$ for $24 \mathrm{~h}$. Thereafter, saturated samples were obtained using the vacuum-extraction method, wherein specimens were placed in a vacuum deaerator for forced saturation for $8 \mathrm{~h}$ and subsequently allowed to rest for $4 \mathrm{~h}$. Sonic-wave tests were performed on the final saturated specimens, and specimens with similar wave velocities were selected as the samples to be used in the tests.

(2) The stress environment of the sandstones was simulated using confining pressure according to the relation $P_{0}=0.013 \times H$, where $P_{0}$ denotes the horizontal in situ stress $(\mathrm{MPa})$ and $H$ denotes the 


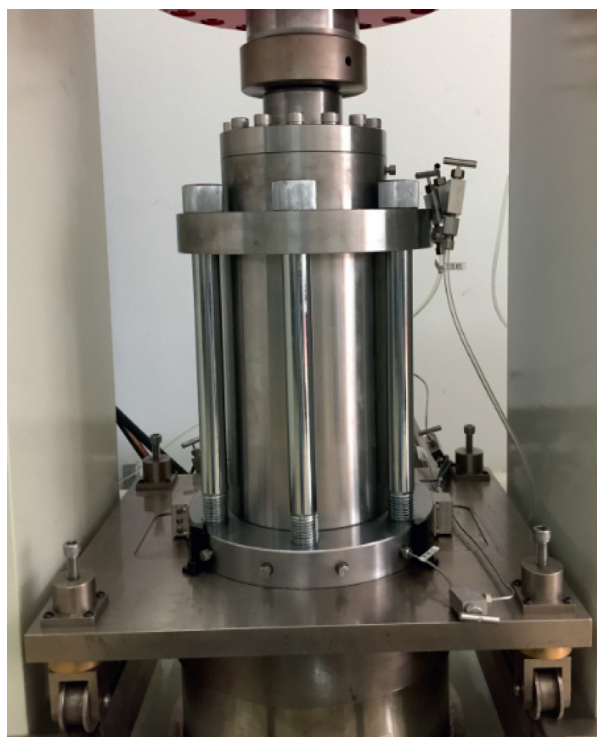

(a)

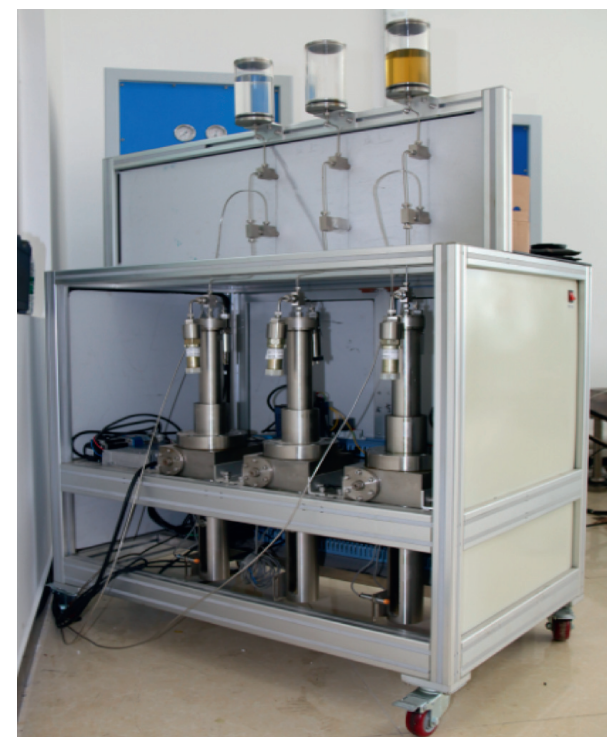

(b)

FIGURE 1: THMC multifield coupling triaxial rheological testing system. (a) Confining pressure chamber. (b) Servo unit for axial, confining, and pore pressures.

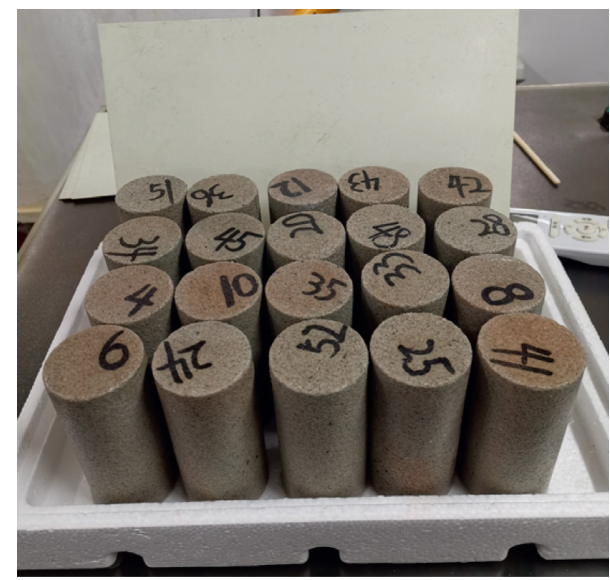

FIGURE 2: Sandstone specimens.

embedded depth (m) [20]. Combined with the actual site data of the embedded depth of the roadway of around $300 \mathrm{~m}$, a confining pressure of $4.0 \mathrm{MPa}$ was determined. The confining and axial pressures were thus increased to $4 \mathrm{MPa}$; subsequently, the confining pressure was maintained constant while the axial pressure was increased until the specimen fractured. The triaxial compressive strength was thus obtained as $\sigma_{c}=32.5 \mathrm{MPa}$, which provided the basis for the unloading test; the loading rate during the test was $0.2 \mathrm{MPa} / \mathrm{min}$.

(3) Five pore pressure gradients $(0,0.1,0.2,0.4$, and $0.6 \mathrm{MPa}$ ) were applied to the sandstone samples during the triaxial unloading test to simulate the different water pressures resulting from changes in the reservoir water levels at specific embedded depths. The axial and confining pressures were loaded as $4.0 \mathrm{MPa}$ at a loading rate of $0.04 \mathrm{MPa} / \mathrm{min}$. Simultaneously, when the confining pressure was greater than the predetermined osmotic pressure, the pore water pressure was applied. Then, the axial pressure was loaded with a predetermined value set to $70 \%$ of the conventional triaxial compressive strength (around 23 MPa). Finally, the confining pressure was unloaded at $0.1 \mathrm{MPa} / \mathrm{min}$ until the specimen fractured. The test plan and basic physical and mechanical parameters of the specimens are summarized in Table 1.

\section{Experimental Results and Analysis}

3.1. Analysis of Deformation Characteristics. To study the response patterns to excavation unloading of the sandstone under the effect of osmotic pressure, triaxial unloading tests were conducted under different pore pressure conditions, and the stress-strain curves corresponding to the entire deformation process were obtained, as shown in Figure 3.

Figure 3 reveals the axial and circumferential deformations to demonstrate linear growth trends during loading stage. Further, the pore-water pressure has a significant effect on sandstone deformation and failure. Under the case with pore water pressure, the deformation patterns were mostly identical during the initial stages of unloading; then, the deformation patterns differed during the failure stages for the different pore water pressures. Specifically, the osmotic pressure had a significant impact on the residual strain; when there was no effect of the pore water pressure, the specimens exhibited ductile failure. The increase in porewater pressure causes the specimens to exhibit gradual brittle failure. During the unloading stage, the increase in the principal-stress difference with pore pressure is more rapid than without it. This can be attributed to the countersupport 
TABle 1: Basic physical parameters of specimens.

\begin{tabular}{|c|c|c|c|c|c|c|c|}
\hline $\begin{array}{l}\text { Test } \\
\text { number }\end{array}$ & Test plan & $\begin{array}{l}\text { Natural } \\
\text { mass (g) }\end{array}$ & $\begin{array}{l}\text { Natural density } \\
\left(\mathrm{g} / \mathrm{cm}^{3}\right)\end{array}$ & $\begin{array}{l}\text { Saturated } \\
\text { mass }(\mathrm{g})\end{array}$ & $\begin{array}{l}\text { Saturated mass } \\
\left(\mathrm{g} / \mathrm{cm}^{3}\right)\end{array}$ & $\begin{array}{l}\text { Saturated wave } \\
\text { velocity }(\mathrm{km} / \mathrm{s})\end{array}$ & $\begin{array}{c}\text { Porosity } \\
(\%)\end{array}$ \\
\hline S-1 & $\begin{array}{l}\text { Unloading without } \\
\text { pore pressure }\end{array}$ & 416.69 & 2.23 & 441.31 & 2.36 & 2.10 & 13.60 \\
\hline S-2 & $\begin{array}{c}\text { Unloading at } 0.1 \mathrm{MPa} \\
\text { pore pressure }\end{array}$ & 410.53 & 2.25 & 434.73 & 2.38 & 2.23 & 13.51 \\
\hline S-3 & $\begin{array}{c}\text { Unloading at } 0.2 \mathrm{MPa} \\
\text { pore pressure }\end{array}$ & 417.83 & 2.22 & 442.17 & 2.35 & 2.10 & 13.36 \\
\hline S-4 & $\begin{array}{l}\text { Unloading at } 0.4 \mathrm{MPa} \\
\text { pore pressure }\end{array}$ & 420.77 & 2.23 & 446.25 & 2.36 & 2.13 & 14.00 \\
\hline S-5 & $\begin{array}{l}\text { Unloading at } 0.6 \mathrm{MPa} \\
\text { pore pressure }\end{array}$ & 415.69 & 2.26 & 439.08 & 2.39 & 2.17 & 13.19 \\
\hline
\end{tabular}

provided to the internal skeleton and sandstone particles by the internal water pressure under the action of the porewater pressure. This is in line with the principle of effective stress proposed by Terzaghi [21].

Additionally, considering the concept of the unloading confining pressure ratio proposed in [22], the designated variable $\Delta \sigma$ was used to describe the unloading confining pressure ratio as

$$
\Delta \sigma=\frac{\Delta \sigma_{3}^{\prime}}{\Delta \sigma_{3}}
$$

where $\Delta \sigma_{3}^{\prime}$ represents the measured confining pressure of the specimen before the stress reduction in the unloading process and $\Delta \sigma_{3}$ represents the unloading confining pressure of the specimen from the beginning of the unloading process until stress reduction.

Combined with the change rates of hoop and volumetric strains, the unloading stage can be divided into three stages as shown in Figures 3(b) and 3(c). When $\Delta \sigma \leq 30 \%$, the change in strain is relatively steady and slow, which is the elastic compaction stage. For $30 \% \leq \Delta \sigma \leq 60 \%$, the unloading development stage, the strain increases rapidly, and circumferential deformation rate is noticeably higher than the axial deformation rate; tensile cracks are gradually initiated, and the trends in volumetric and hoop strains are identical, causing the specimen to gradually fracture. In particular, when the confining pressure is unloaded to around $\Delta \sigma=50 \%\left(\sigma_{1}-\sigma_{3}=21.5 \mathrm{MPa}\right)$, the deformation increases rapidly. For $60 \%<\Delta \sigma \leq 90 \%$, the circumferential deformation rate is relatively slow, and internal cracks gradually connect to form fractures until the stress reduces (specimen failure). Overall, it is observed that the deformation of sandstone is significantly affected by the circumferential deformation; further, after the fracture of sandstone (after the stress drops), the hysteresis effect can be seen in the hoop and volumetric strains owing to the low confining pressures of the experimental design. After the specimen fractures, the axial pressure compacts the specimen, resulting in a decrease in strain.

Rocks exhibit different deformation characteristics under different pore-water pressure conditions, and the resulting deformation characteristics include different residual strains and elastic modulus of each stage. Based on the above observation, the unloading seepage test was divided into the loading, unloading (elastic, development, and propagation stages), and stress drop stages. Then, statistical analyses of the elastic moduli of the specimens for each of the five stages were performed to obtain the characteristic parameters of unloading seepage deformation shown in Table 2; this data was used to perform statistical regression analysis (Figure 4).

It is seen from Figure 4 that there is a good linear relationship between the residual strain and pore pressure; the greater the pore pressure, the greater the absolute value of the residual strain. After entering the unloading stage, the elastic modulus begins decreasing. Moreover, the elastic moduli at various unloading stages decrease significantly with the increase in pore pressure. During the unloading development and propagation stages, these reductions become more apparent, thereby indicating gradual specimen deformation and failure. This significantly affects the elastic modulus of the specimen causing it to deform and fail during the stress-drop stage. At this point, the elastic modulus reduces to approximately $35 \%$ of its corresponding loading-stage value.

3.2. Analysis of Strength Characteristics. Although the failure angles and fracture characteristics of the specimens under different pore water pressure states were considerably different, all the main cracks exhibited oblique shear or compression-shear characteristics (Figures 5 and 6). Under the condition of low pore-water pressure, failure occurred with a single dominant crack. When the pore water pressure reached $0.6 \mathrm{MPa}$, a " $V$ " type failure occurred. With additional continuous increase in the water pressure, the corresponding peak deviatoric stress first increased and then gradually decreased as $22.79 \mathrm{MPa} \longrightarrow 23.16$ $\mathrm{MPa} \longrightarrow 23.15 \mathrm{MPa} \longrightarrow 22.93 \mathrm{MPa} \longrightarrow 22.41 \mathrm{MPa}$; the failure and deformation gradually shifted from shear failure to hybrid compression-shear failure and from a single dominant crack to multiple overlapping cracks. It was assumed that the reason for the emergence of this type of macrofracture characteristic was the shear stress that is inevitably generated in the crack initiation and propagation directions inside the specimen during the stress unloading process; thus, all specimens showed shear failure characteristics. Moreover, the hydromechanical coupling effect was not significant when the pore water pressure was low; when the 

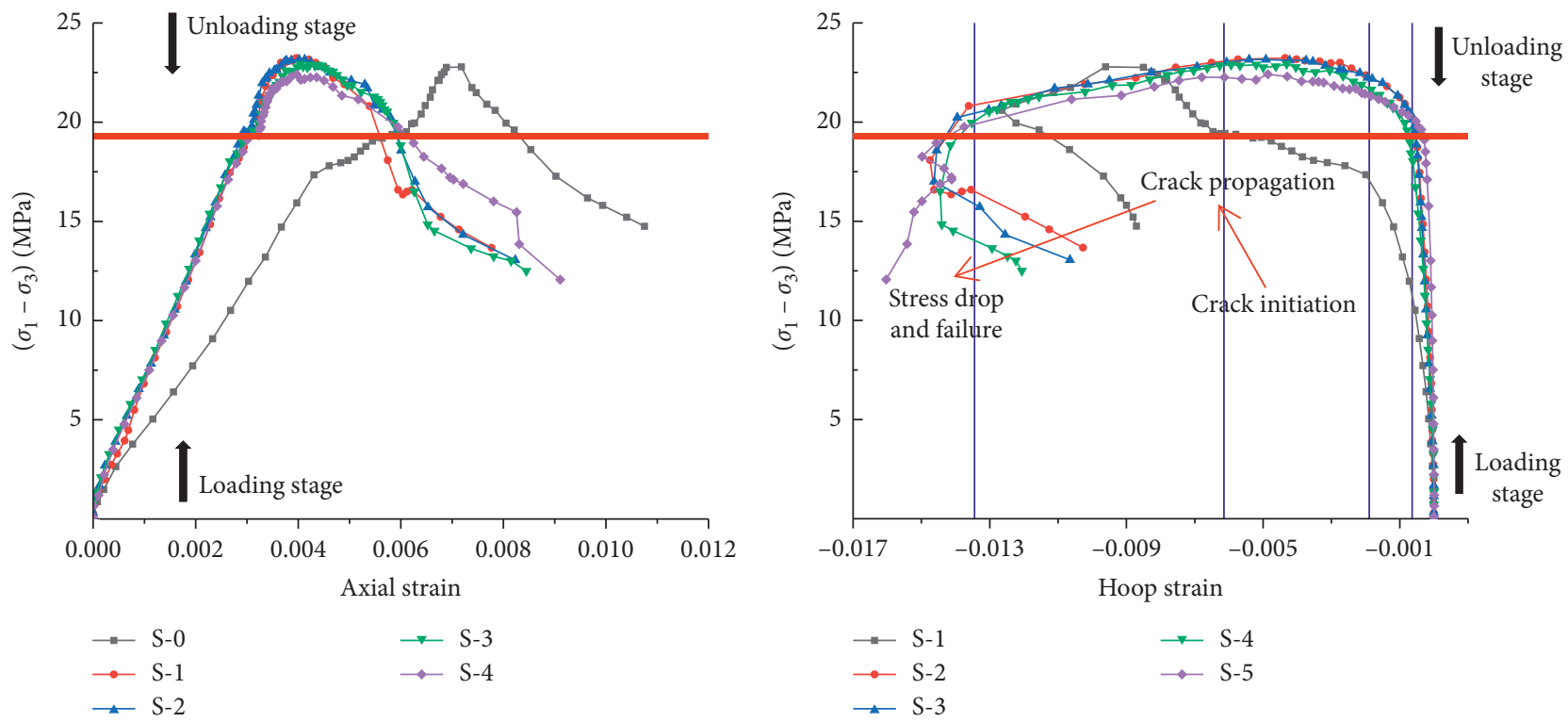

(a)

(b)

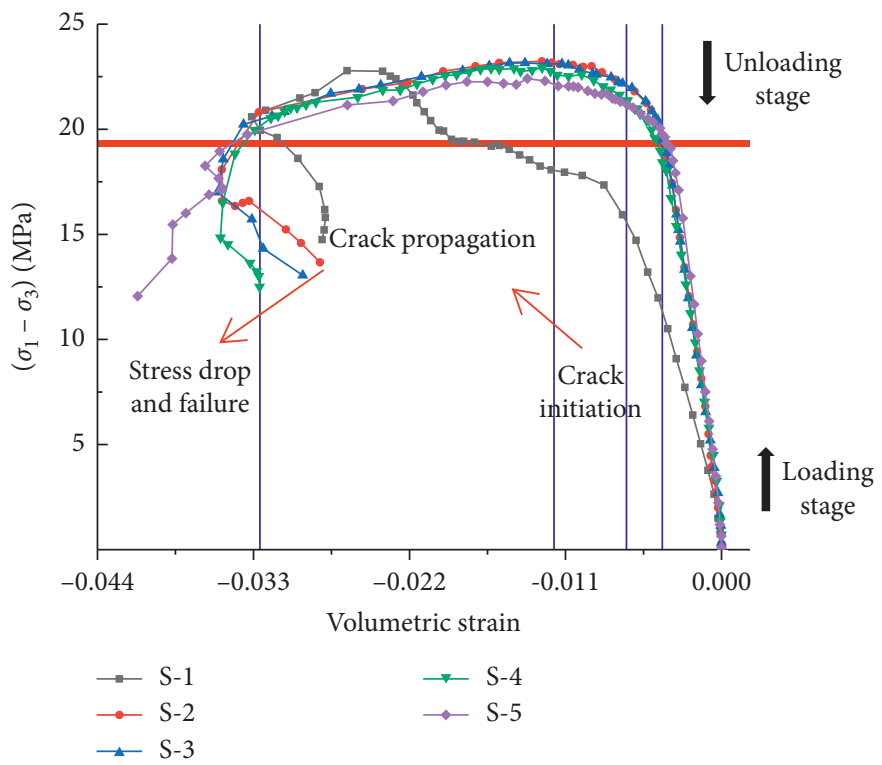

(c)

FIGURE 3: Stress-strain relationship curves for specimens used in this study. (a) Variation of $\left(\sigma_{1}-\sigma_{3}\right)$ with $\varepsilon_{1}$. (b) Variation of $\left(\sigma_{1}-\sigma_{3}\right)$ with $\varepsilon_{3}$. (c) Variation of $\left(\sigma_{1}-\sigma_{3}\right)$ with $\varepsilon_{V}$.

TABLE 2: Characteristic parameter values during unloading seepage deformation.

\begin{tabular}{|c|c|c|c|c|c|c|c|c|}
\hline $\begin{array}{l}\text { Test } \\
\text { number }\end{array}$ & $\begin{array}{c}\text { Pore } \\
\text { pressure } \\
(\mathrm{MPa})\end{array}$ & $\begin{array}{l}\text { Residual } \\
\text { hoop strain }\end{array}$ & $\begin{array}{c}\text { Residual } \\
\text { axial strain }\end{array}$ & $\begin{array}{l}\text { Loading } \\
\text { stage, } E \\
(\mathrm{GPa})\end{array}$ & $\begin{array}{c}\text { Unloading } \\
\text { stage (elastic), } E \\
(\mathrm{GPa})\end{array}$ & $\begin{array}{l}\text { Unloading stage } \\
\text { (development), } E \\
\text { (GPa) }\end{array}$ & $\begin{array}{c}\text { Unloading stage } \\
\text { (propagation), } E \\
(\mathrm{GPa})\end{array}$ & $\begin{array}{l}\text { Stress } \\
\text { drop } \\
\text { stage, } E \\
(\mathrm{GPa})\end{array}$ \\
\hline S-2 & 0.1 & -0.0102 & 0.0078 & 7.76 & 6.86 & 6.67 & 5.68 & 2.59 \\
\hline$S-3$ & 0.2 & -0.0106 & 0.0080 & 7.78 & 6.89 & 6.51 & 5.56 & 2.56 \\
\hline S-4 & 0.4 & -0.0121 & 0.0085 & 8.07 & 6.90 & 6.14 & 4.53 & 2.12 \\
\hline S-5 & 0.6 & -0.0160 & 0.0091 & 8.28 & 6.59 & 5.88 & 3.92 & 2.06 \\
\hline
\end{tabular}




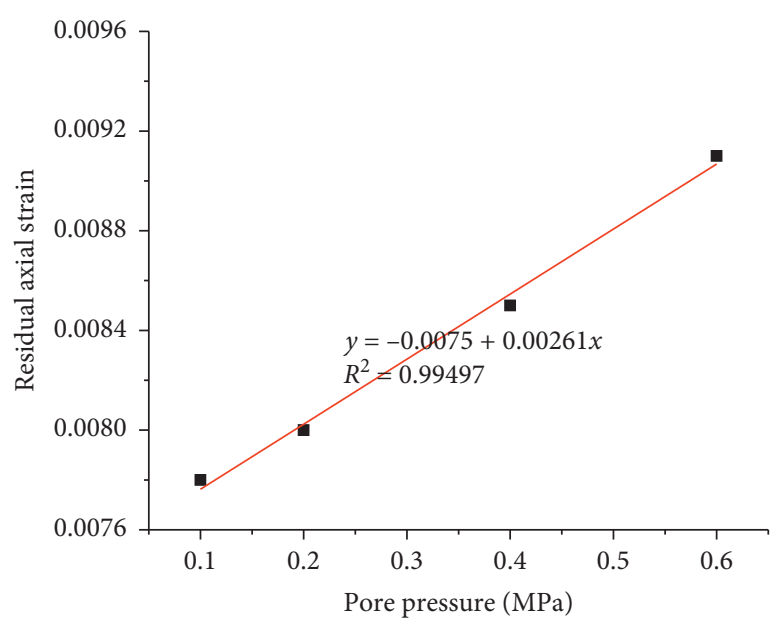

(a)

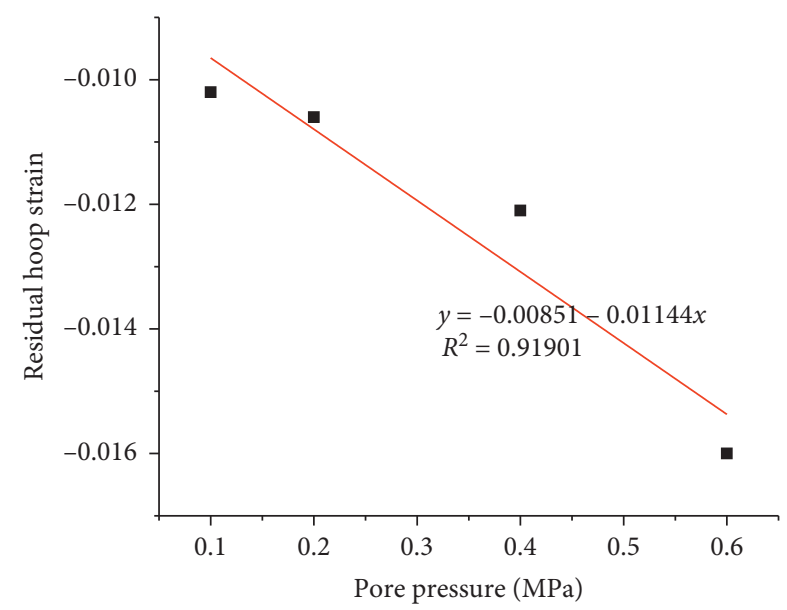

(b)

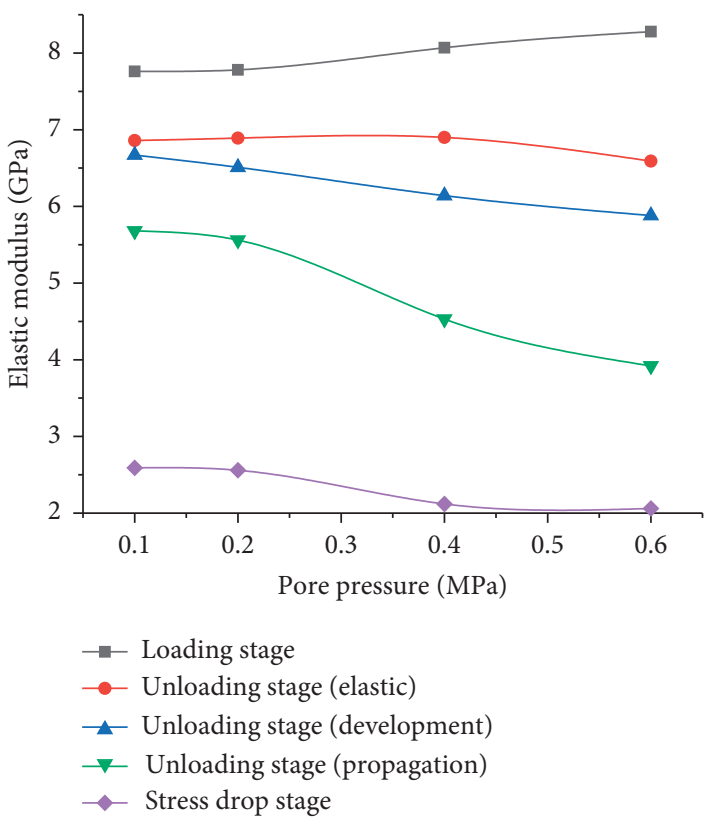

(c)

Figure 4: Variations in residual strain and elastic modulus with pore pressure. (a) Variation in residual axial strain with pore pressure. (b) Variation in residual hoop strain with pore pressure. (c) Variation in elastic modulus with pore pressure.

pore water pressure reached $0.6 \mathrm{MPa}$, the hydromechanical coupling effect gradually manifested, which promoted compression deformation of the specimen and formation of more compression cracks, showing compression-shear failure characteristics. The corresponding axial strain under the peak deviatoric stress changed as $0.392 \% \longrightarrow$ $0.402 \% \longrightarrow 0.404 \% \longrightarrow 0.412 \%$. This gradual increase can be considered as a verification. Additionally, owing to the small pore pressure gradient selected in this work, the change in axial strain was not apparent.

Cai et al. [23, 24] divided the stress-strain curves of rocks into four stages based on the state of development of the cracks within the rocks. Stage I is for closure and compression of the preexisting crack, Stage II is the linear elastic stage, Stage III is for stable crack growth, and Stage IV is the nonlinear growth stage. The end points of these stages correspond to the crack closure stress $\sigma_{c c}$, crack initiation stress $\sigma_{c i}$, crack-damage stress $\sigma_{c d}$, and peak stress $\sigma_{c}$. Among them, the crack initiation stress $\sigma_{c i}$ and crackdamage stress $\sigma_{c i}$ are the two important parameters that characterize rock strength.

The damage stress $\sigma_{c i}$ represents the starting point of stable crack growth in rocks, i.e., the crack initiation point. Thereafter, external loading is necessary to drive the propagation of cracks inside the specimens. The crackdamage stress $\sigma_{c d}$ is the starting point of the nonlinear crack growth, i.e., the volume expansion point. A large number of cracks inside the specimen continue to grow and form larger cracks from the external force; this stage is not required to drive growth. In this work, the volumetric strain method was used to determine the characteristic strength and variation in characteristic strength of the unloading seepage of the 


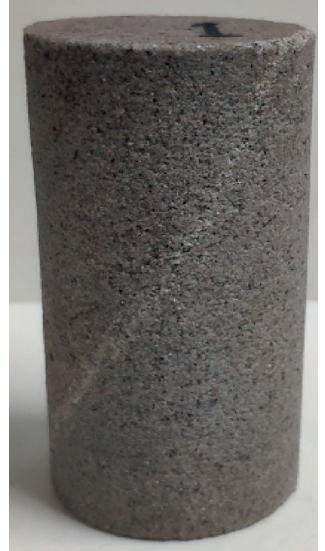

(a)

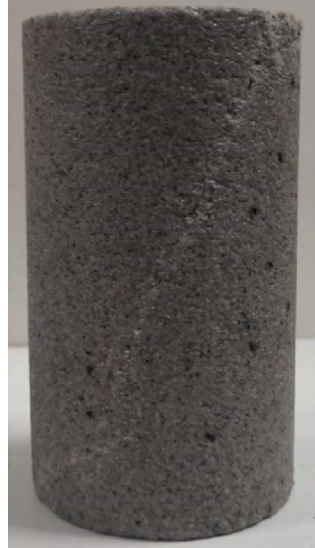

(b)

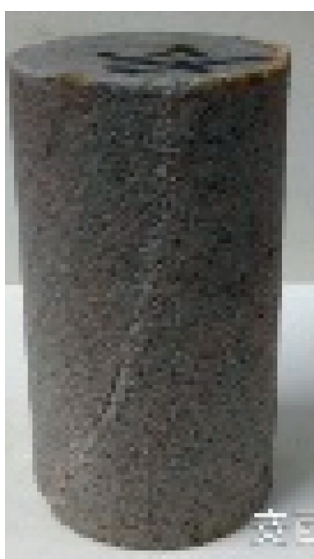

(c)

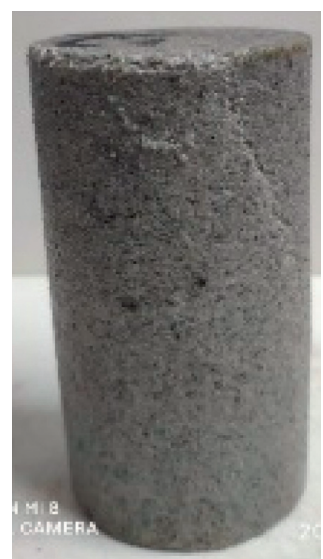

(d)

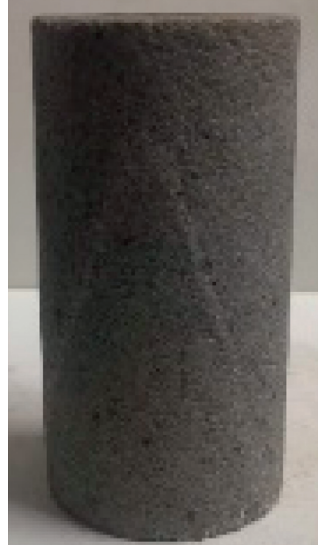

(e)

FIgURE 5: Typical specimen-fracture characteristics. (a) No pore pressure. (b) $0.1 \mathrm{MPa}$ pore pressure. (c) $0.2 \mathrm{MPa}$ pore pressure. (d) $0.4 \mathrm{MPa}$ pore pressure. (e) $0.6 \mathrm{MPa}$ pore pressure.

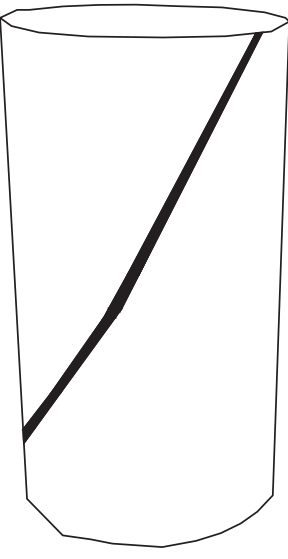

(a)

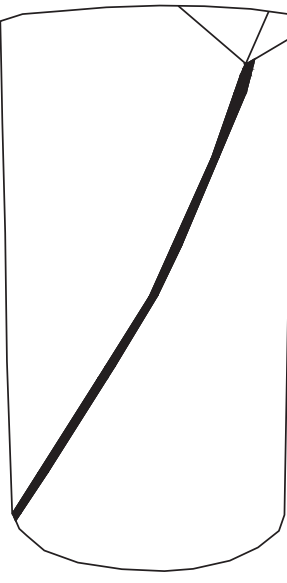

(b)

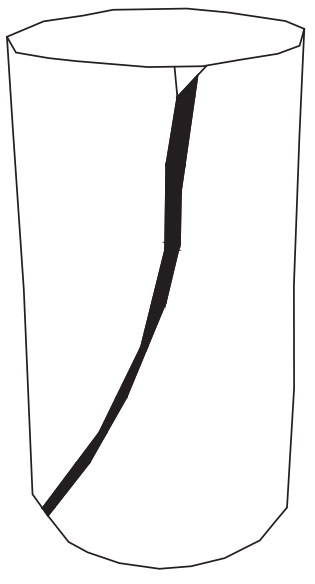

(c)

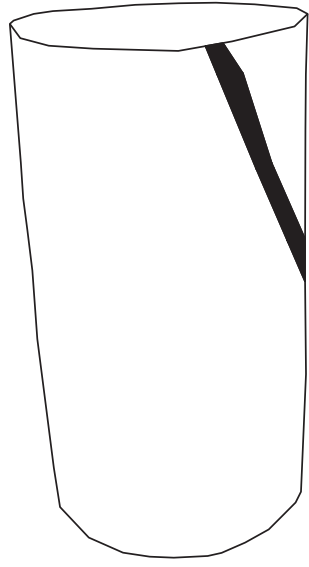

(d)

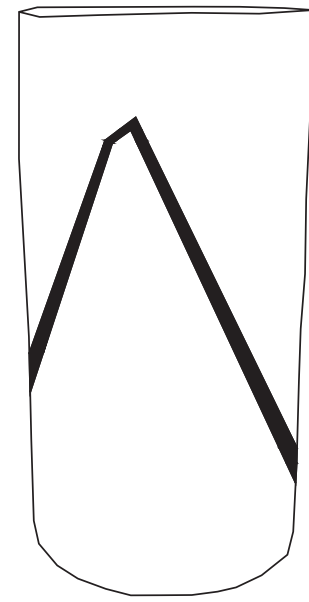

(e)

Figure 6: Sketch maps of specimen-fracture characteristics. (a) Pore pressure 0. (b) Pore pressure 0.1 MPa. (c) Pore pressure $0.2 \mathrm{MPa}$. (d) Pore pressure 0.4 MPa. (e) Pore pressure 0.6 MPa.

specimen under the action of pore water pressure. According to Figure 3(c), the characteristic values of the crack initiation stress $\sigma_{c i}$ and crack-damage stress $\sigma_{c d}$ are shown in Table 3, which are fitted and plotted in Figure 7.

It is seen from Table 3 that with the increase in water pressure, $\sigma_{c i}$ and $\sigma_{c d}$ gradually decrease, indicating that the crack initiation point of the specimen gradually decreases under the action of pore water pressure; i.e., crack initiation occurs in the rock at lower deviatoric stress values. In this experiment, the deformation and failure of the specimen were more sensitive to changes in the confining pressure with increase in water pressure, with more rapid responses. A small decrease in the confining pressure would thus cause initiation of cracks in the specimen. Besides, the difference between Stage III and Stage IV gradually decreases, indicating that the time between crack initiation and volume expansion reduces such that the conversion process is hastened. The pore water pressure will force the rock to quickly go through the crack initiation stage and enter the crack propagation and growth stages under the same of in situ stress environment. The pore water pressure thus has a significant promoting effect on the deformation and failure of rocks. Therefore, problems related to water pressures in practical engineering scenarios in mine roadways necessitate countermeasures.

3.3. Analysis of Structural Characteristics of Pores. During the experiments, the water outlet was closed to form an environment with stable pore water pressure in the tank. When the pore structure in the specimen changed, the flow rate of the water inlet inevitably changes; $\Delta Q_{m}$ was defined as the change in the flow rate of the water inlet between time $m$ and the start time:

$$
\Delta Q_{m}=Q_{m}-Q_{0},
$$


TABLE 3: Strength characteristic values of unloading seepage.

\begin{tabular}{lccc}
\hline Test number & Water pressure $(\mathrm{MPa})$ & $\sigma_{c i}(\mathrm{MPa})$ & $\sigma_{c d}(\mathrm{MPa})$ \\
\hline S-2 & 0.1 & 21.80 & 22.70 \\
S-3 & 0.2 & 21.34 & 22.61 \\
S-4 & 0.4 & 19.97 & 21.88 \\
S-5 & 0.6 & 19.34 & 21.16 \\
\hline
\end{tabular}

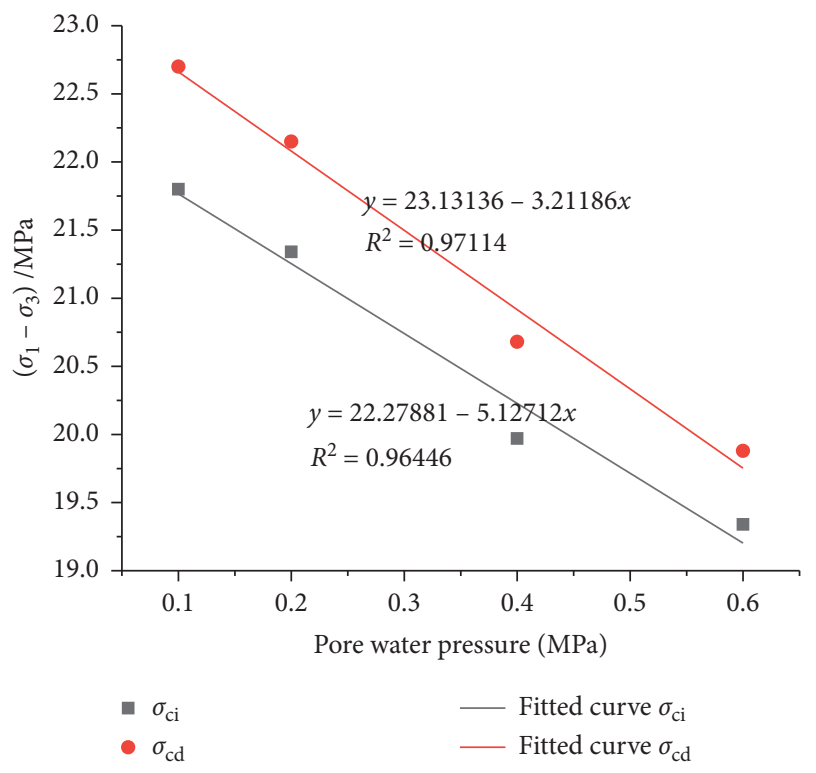

FIGURE 7: Strength characteristics of unloading seepage.

where $Q_{m}$ denotes the flow rate at the water inlet at time $m$, and $Q_{0}$ is the flow rate at the water inlet at the start time.

When $\Delta Q_{m}>0$, the pore structure is understood to expand and develop. When $\Delta Q_{m}<0$, the pore structure is understood to shrink and close. The variation in $\Delta Q_{m}$ was therefore analyzed to characterize the changes in pore structures in the specimen. The relationship between the volumetric strain and water inflow at different pore pressure gradients can be plotted as shown in Figure 8.

Before failure, a four-stage evolution process of slow development $\longrightarrow$ rapid increase $\longrightarrow$ slight decrease $\longrightarrow$ sharp increase was observed in the specimen with change in the volumetric strain. Combined with the analysis of the stress path, it was observed that the change in water inflow was consistent with the variations in the deformation and strength characteristics. The change in water inflow was correlated with the process of initial microcrack compaction, stable crack growth, and crack propagation. Under various working conditions, the sandstone specimens exhibited noticeable linear elastic deformation characteristics in the loading and unloading elastic stages. During these phases, the specimens were close to being elastic bodies, and the water inflow first remained unchanged but slightly decreased later. In the stable and unstable crack propagation stages during the unloading process, the internal cracks grew and propagated rapidly, and the number and width of pore throats for seepage gradually increased, causing a gradual increase in the water inflow. At the stress drop stage, the

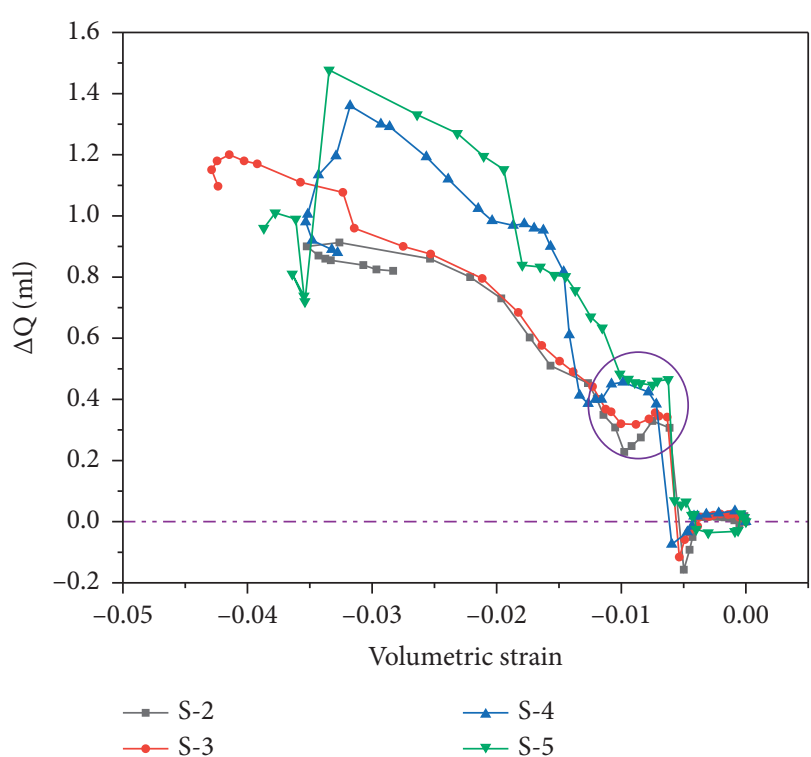

Figure 8: Curves demonstrating the relationship between sandstone seepage unloading and inflow.

"shrinkage" phenomenon occurred in the specimen after failure owing to axial pressure, which resulted in a decrease in the water inflow.

The water inflow of the specimens decreased after the stable microcrack development stage owing to gradual failure of the specimens after stable crack propagation, and the internal cracks entered the nonlinear development stage. The brittleness of the sandstone specimens was relatively apparent. Free water failed to diffuse to the crack tip in time, thus weakening the effect of the pore water pressure. Microfractures and pores that manifested in the specimens were compacted by the confining and axial pressures, resulting in a decrease in the fracture aperture and narrowing of the pore throats for seepage. Nevertheless, the duration of this process was short, and the specimens quickly entered the crack initiation and propagation stages, with rapid volume expansion. As the osmotic pressure increased, this phenomenon gradually became insignificant.

With the increase in osmotic pressure, the water inflow gradually increased. For example, the maximum change in water inflow was $0.91 \mathrm{~mL}$ when the osmotic pressure was $0.1 \mathrm{MPa}$, while it was $1.48 \mathrm{~mL}$ when the osmotic pressure was $0.6 \mathrm{MPa}$, showing an increase of 1.62 times. This is mainly because higher values of osmotic pressure weaken the radial inhibiting effect of the confining pressure on the specimen, and stronger hydromechanical couplings cause propagation and growth of cracks in the specimen, forming macroscopic fractures. The pore throats for seepage opened completely, leading to increased water inflow. After the maximum water inflow was attained, the specimen quickly entered the stress drop stage and failed, which can be considered as a precursor to deformation and failure. The osmotic pressure was inversely proportional to the volumetric strain required to reach the maximum water inflow; for instance, the volume strain rate was $0.35 \%$ at $0.1 \mathrm{MPa}$, while it was $0.33 \%$ at $0.6 \mathrm{MPa}$. 


\section{Numerical Simulation and Engineering Application}

4.1. Numerical Simulation. In this study, mining extractions were performed in coal seam \#16 in a mine located in western China. The seam had an average thickness of $8.8 \mathrm{~m}$, an inclination of $8-18^{\circ}$, and a hardness coefficient $f \leq 3$. Between the coal seams and the water in the reservoir area, mainly the carboniferous system, Shiqianfeng formation, Shihezi formation, and Shanxi formation were noted. The lithology mainly included sandstone, shale, and sandy shale, with a thickness of around $300 \mathrm{~m}$. The regional geological structure was relatively simple, with two waterproof strata and five water-bearing strata above the roof of the roadway. The local roof was relatively fragmented, and the fractures in the roof and floor as well as in the coal seam were relatively developed. The coal-mining methods used include the retreating longwall, fully mechanized top coal caving, and mining along the bottom while considering a 1:1.93 drawing ratio.

After the reservoir was filled, there was a hydraulic connection between the tertiary coal seam and the water in the reservoir area. The limestone in the northeast part of the mining area encounters the main coal seam owing to faulting (F2). The $60 \mathrm{~m}$-thick fault-fracture zone F2 was exposed through the borehole; its bottom part was filled with a sandy material and had high water conductivity. The sandstones were thick and broadly distributed. The water in the reservoir area flowed into these water-bearing strata through the fault-fracture zone with high permeability and became the main source of water in the mining area. The schematic of the hydrogeological structure is shown in Figure 9(a). According to the diagram, a numerical calculation model was established using the UDEC simulation software (Figure 9(b)). Water pressures of $0.1 / 0.4 / 0.6 /$ 1.0 $\mathrm{MPa}$ were applied to the top of the model, and the Mohr-Coulomb constitutive model was adopted. The Bingham constitutive model $[25,26]$ was also adopted for diffusion and flow of water. The rock-mechanics parameters used are shown in Tables 4 and 5 .

Survey lines were set up in the middle of the roadway roof to monitor the vertical displacement and relative separation of the surrounding rocks on the roof. The monitoring results are shown in Figure 10. It is seen from Figure 10 that as the water pressure increases, the subsidence of the roadway roof gradually increases, with changes proceeding in the order $16.1 \mathrm{~cm} \longrightarrow 16.3 \mathrm{~cm} \longrightarrow$ $25.1 \mathrm{~cm} \longrightarrow 27.1 \mathrm{~cm}$. In particular, when the water pressure increased from $0.4 \mathrm{MPa}$ to $0.6 \mathrm{MPa}$, the roof subsidence increased significantly, indicating the existence of a certain water pressure threshold. Moreover, this phenomenon is consistent with the results of the unloading seepage test, where the deformation and failure of the specimen are more severe when the pore pressure exceeds 0.6 MPa. When the water pressure was low, the degree of separation of the shallow surrounding rocks $(\leq 2 \mathrm{~m})$ was significantly lower than that when the water pressure was high. In the transition to the deep surrounding rocks $(3-7 \mathrm{~m})$, the change in the relative separation of the surrounding rocks varied. In general, this change was proportional to the water pressure. As the transition advances to the deep surrounding rocks $(\geq 7 \mathrm{~m})$, the change in the relative separation of the surrounding rocks was not noticeable, and the correlation with the change in the water pressure was weak.

Figure 11 shows the statistics of the joint development and development of fractures around the roadway, where the green line is the outline of the roadway, yellow represents the fracture area formed by joint opening, magenta represents the fracture area formed by joint dislocation, and red represents the mixed fracture area. It is observed that the fractures in the surrounding rocks are dominated by the dislocation fracture area. The number of joints gradually increases with the increase in water pressure. Nonetheless, when the water pressure is $0.6 \mathrm{MPa}$, the rate of increase drops significantly; at low water pressures (0.1-0.4 MPa), the two ribs of the roadway were mainly dislocation fracture areas, with unnoticeable fractures on the roof. At high water pressures $(0.6-1.0 \mathrm{MPa})$, the dislocation fracture areas propagate from the two ribs to the top of the roadway, overlapping with the open fractures and forming mixed fractures, thereby forming a large area penetrated by fractures in the surrounding rocks of the roadway and resulting in significant shrinkage in the outline of the roadway. The roadway was thus severely deformed, affecting production safety. Hence, it is noted that the protection of the coal rib during roadway excavation under water disturbance is of critical importance.

The nephogram of the pore water pressure and survey line data of the surrounding rocks of the roadway are shown in Figure 12. It is seen from Figure 12 that with the increase in water pressure, the impact, the area of action of the water pressure gradually increases. Roof fractures develop in an intertwining manner, and fractures in the strata surrounding the upper part of the roadway roof are connected. The water flow was relatively free in this area, resulting in a reduction in the difference between various horizontal survey line data (Figures 12(c) and 12(d)). At a water pressure of $0.1 \mathrm{MPa}$, no pore water pressure was observed on the horizontal survey line at the coal seam of the roadway roof. However, when the water pressure was $0.6 \mathrm{MPa}$, the pressure of the horizontal survey line of the strata of the roadway roof approached $0.3 \mathrm{MPa}$, and the pore pressure inside various strata of the roadway roof gradually increased, resulting in enhanced water-rock coupling, thereby deepening and aggravating the disturbance to the rocks surrounding the roadway. The vertical survey line was analyzed, and it was observed to have sharply dropped within a certain range of the surrounding rocks above the roadway owing to excavation unloading. This can be considered as the range of roadway-roof disturbance caused by water pressure. By comparison, it was found that the roof disturbance changed as follows: $11.5 \mathrm{~m} \longrightarrow 12.5 \mathrm{~m} \longrightarrow 15 \mathrm{~m} \longrightarrow 16.5 \mathrm{~m}$, and the range of disturbance of the roof increased significantly. Furthermore, owing to the joint angles of the numerical model, water gathered to the left under the action of gravity, causing the pore pressure near the model boundary on the left side to be greater than that on the right side. 


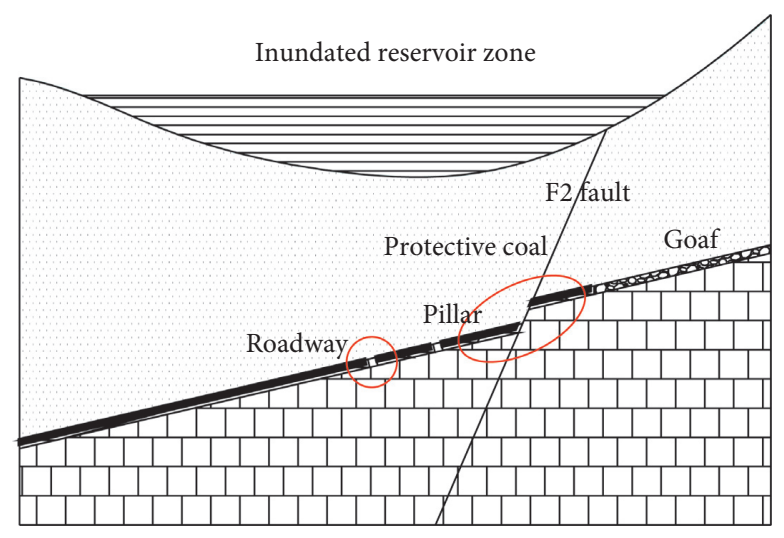

(a)

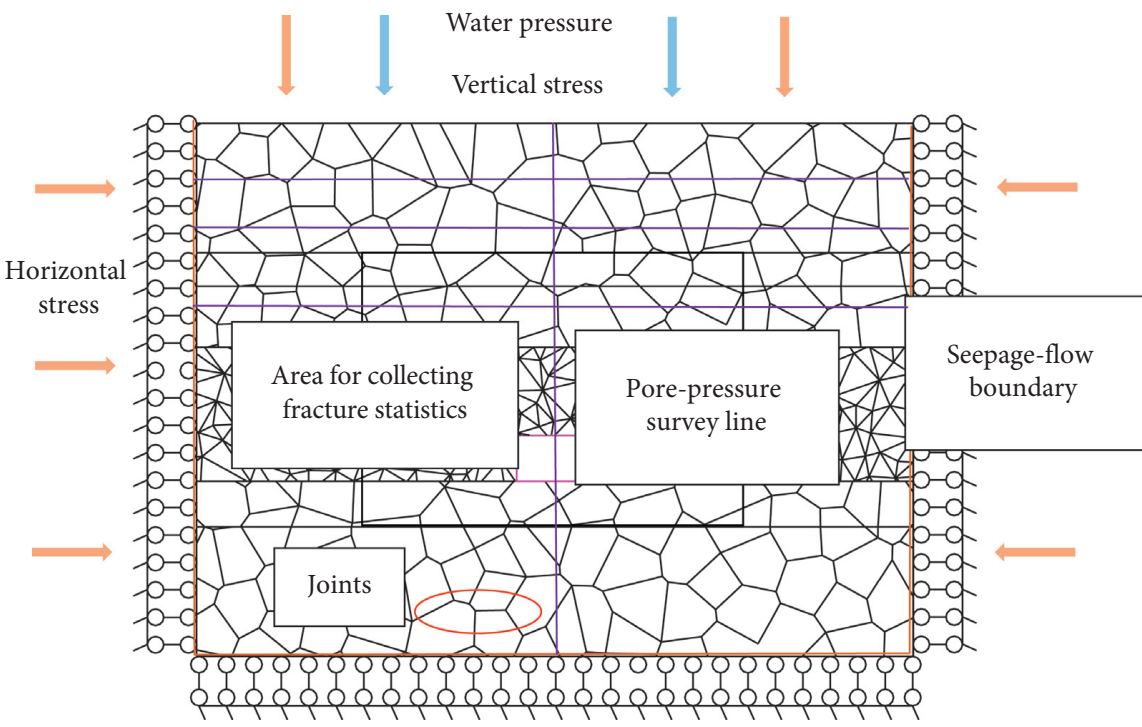

(b)

FIgURE 9: Hydrogeological and numerical calculation models. (a) Schematic of hydrogeological structure. (b) Numerical calculation model.

TABLE 4: Major parameters of rock mechanics.

\begin{tabular}{lcccccc}
\hline Lithology & $\begin{array}{c}\text { Density } \\
\left(\mathrm{kg} / \mathrm{m}^{3}\right)\end{array}$ & $\begin{array}{c}\text { Bulk modulus } \\
(\mathrm{GPa})\end{array}$ & $\begin{array}{c}\text { Shear modulus } \\
(\mathrm{GPa})\end{array}$ & $\begin{array}{c}\text { Cohesive strength } \\
(\mathrm{MPa})\end{array}$ & $\begin{array}{c}\text { Internal friction angle } \\
\left({ }^{\circ}\right)\end{array}$ & $\begin{array}{c}\text { Tensile strength } \\
(\mathrm{MPa})\end{array}$ \\
\hline Fine sandstone & 2500 & 0.85 & 0.4 & 1.87 & 30 & 2.15 \\
Mudstone & 1780 & 0.65 & 0.3 & 1.82 & 28 & 2.15 \\
Coal & 2450 & 0.4 & 0.2 & 1.71 & 28 & 1.69 \\
Medium & 2750 & 1.85 & 0.85 & 1.88 & 33 & 2.04 \\
sandstone & & & & & \\
\hline
\end{tabular}

TABLE 5: Mechanical parameters of joint.

\begin{tabular}{lccccc}
\hline Lithology & $\begin{array}{c}\text { Normal stiffness } \\
(\mathrm{GPa})\end{array}$ & $\begin{array}{c}\text { Tangential stiffness } \\
(\mathrm{GPa})\end{array}$ & $\begin{array}{c}\text { Cohesion } \\
(\mathrm{MPa})\end{array}$ & $\begin{array}{c}\text { Internal friction angle } \\
\left({ }^{\circ}\right)\end{array}$ & $\begin{array}{c}\text { Tensile strength } \\
(\mathrm{MPa})\end{array}$ \\
\hline Fine sandstone & 2.8 & 1.7 & 0.3 & 30 & 0.4 \\
Mudstone & 2.1 & 1.3 & 0.2 & 28 & 0.3 \\
Coal & 0.9 & 1.5 & 0.1 & 28 & 0.2 \\
Medium & 3.5 & 2 & 0.4 & 33 & 0.5 \\
sandstone & & & & \\
\hline
\end{tabular}




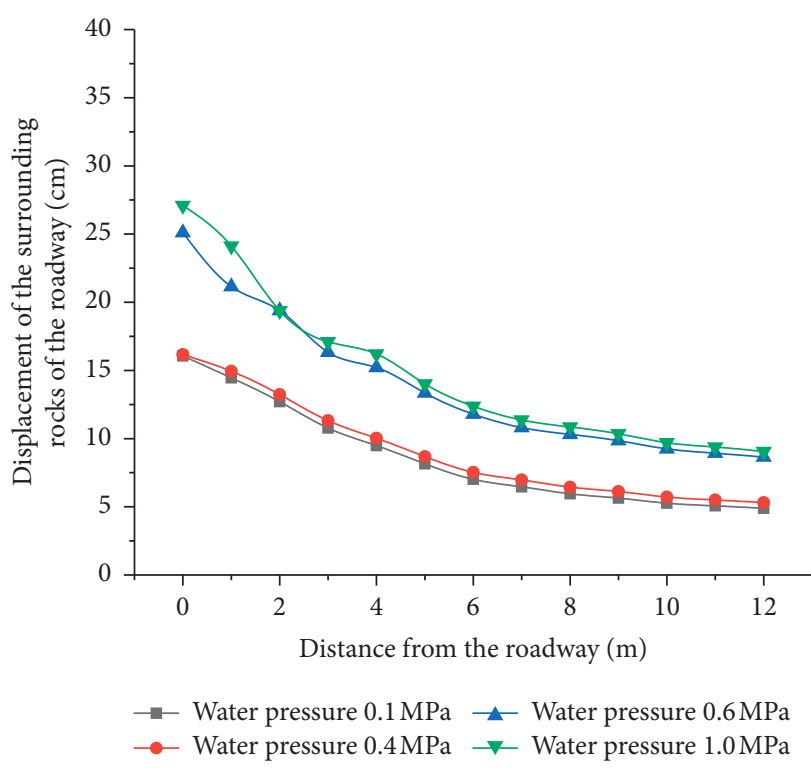

(a)

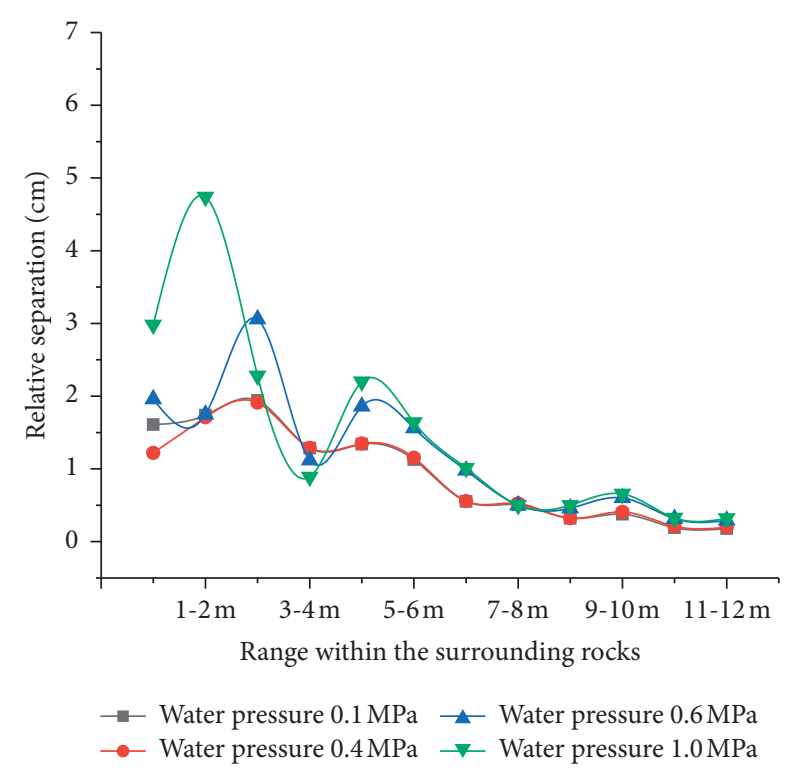

(b)

FIGURE 10: Variations in vertical displacement and relative separation of roof. (a) Vertical displacement of rocks surrounding the roof. (b) Relative separation of rocks surrounding the roof.

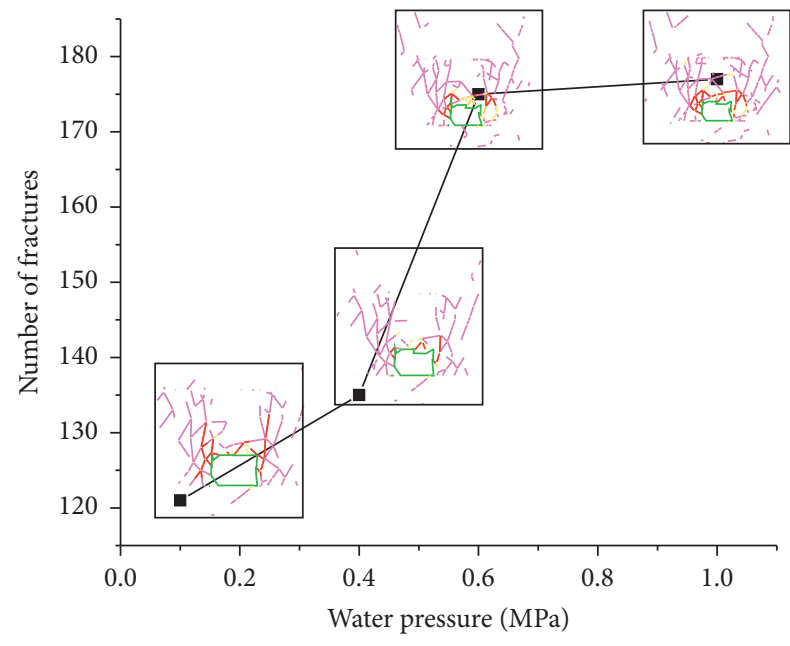

Figure 11: Roadway fracture development.

4.2. Engineering Application. Surface reservoirs, wherein noticeable water-rock interactions are observed, demonstrate a more significant effect of excavation unloading. This, in turn, results in increased roadway deformation, which causes rock-bolt breakage, steel-band falling, and roof subsidence, thereby affecting production safety. These failures are depicted in Figure 13.

In view of the specific conditions of mine roadways, the following support plan was specially developed. The roof and ribs were supported by high-performance rock bolts and reinforced with anchor cables. Diamond-shaped metal meshes combined with $\mathrm{W}$-shaped steel bands were used for protection. Anticlockwise-rotating high-strength ribbed steel rock bolts without longitudinal ribs and dimensions $\phi 22 \times \mathrm{M} 24 \times 2000 \mathrm{~mm}$ were used to support the roof and two ribs. The intervals between the rock bolts were $700 \mathrm{~mm} \times 700 \mathrm{~mm}$. Each rock bolt was equipped with two extended anchorages of the Z2350 medium setting resin capsule. The dimensions of the steel strands of the anchor cables are $\phi 17.8 \times 6.8 \mathrm{~m}$. The boreholes were $6.5 \mathrm{~m}$ in depth, with intervals of $1.4 \mathrm{~m} \times 1.4 \mathrm{~m}$. Four sections of extended anchorages of the Z2350 medium setting resin capsule were used in each borehole. The pretightening force used was $120 \mathrm{kN}$, and the support plan is shown in Figure 14.

To explore the scientific nature of this support plan, three observation stations were set up in the north wing of the roadway. The borehole observation stations, which were all located in the middle of the roadway roof, were set up at distances of $160 \mathrm{~m}, 250 \mathrm{~m}$, and $340 \mathrm{~m}$ from the excavation face, with a borehole depth of $10 \mathrm{~m}$. The borehole observation videos were analyzed, and representative screenshots were selected for explanation, as shown in Figure 15.

It is seen from Figure 15(a) that uneven fractures and weak planes were distributed in the surrounding rocks within $1.4 \mathrm{~m}$. The integrity of the surrounding rocks within the range of $1.4 \mathrm{~m}$ to $4.0 \mathrm{~m}$ was not high. The phenomenon of a fracture zone intersecting with multiple fractures occurred in some areas, while the strata were relatively intact, and no fractures were found in the remaining areas. It is seen from Figure 15(b) that over time, the surrounding rocks were relatively fractured within the range of $1.3 \mathrm{~m}$. Within the range of $1.3 \mathrm{~m}$ to $2.4 \mathrm{~m}$, the strata were relatively intact in the anchoring section, with no fractures, and the strata in the remaining areas were all relatively complete. It is seen from Figure 15(b) that two months after the construction of the observation station, the roadway has entered the phase of stable excavation, with the fracture zone and fractures of the surrounding rocks shifting towards the deep surrounding rocks. In summary, the stress of the roadway roof was 

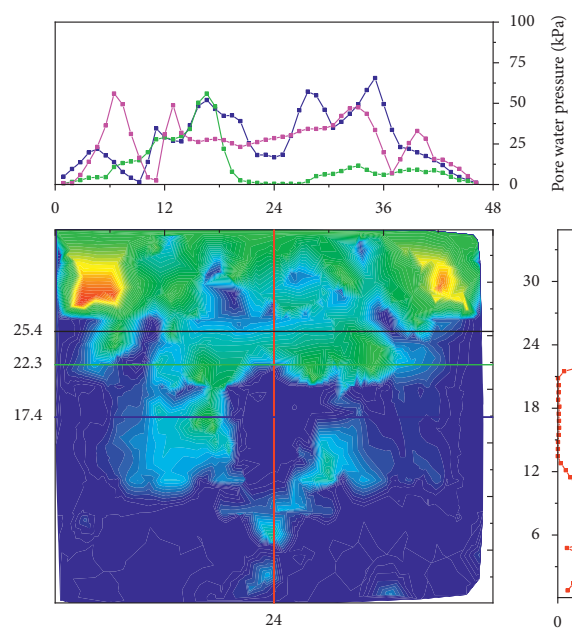

(a)
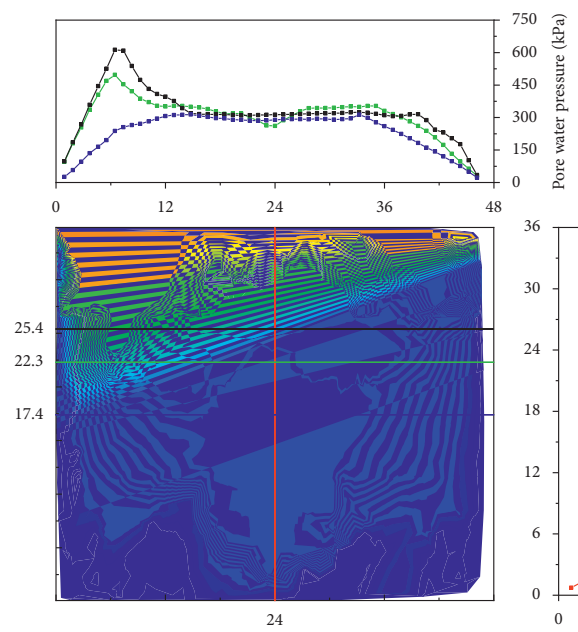

(c)

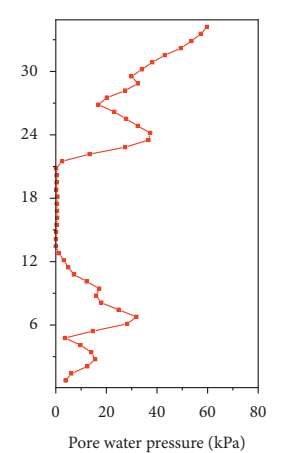

Pore water pressure $(\mathrm{kPa})$

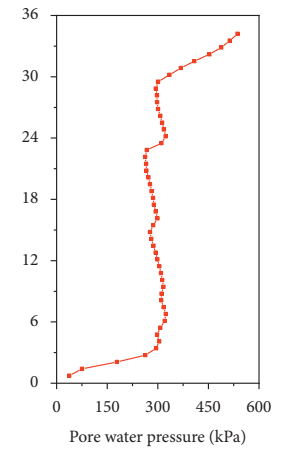

Pore water pressure $(\mathrm{kPa})$

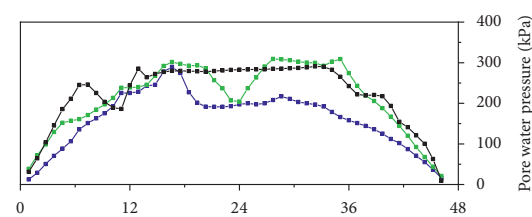

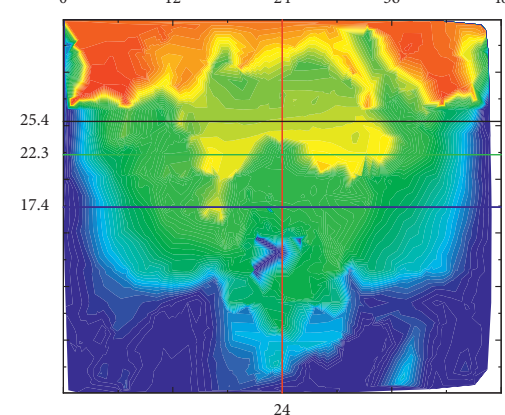

(b)
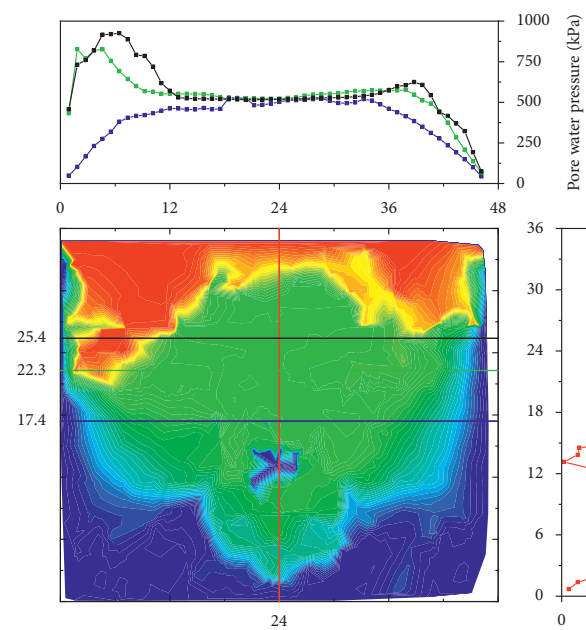

(d)
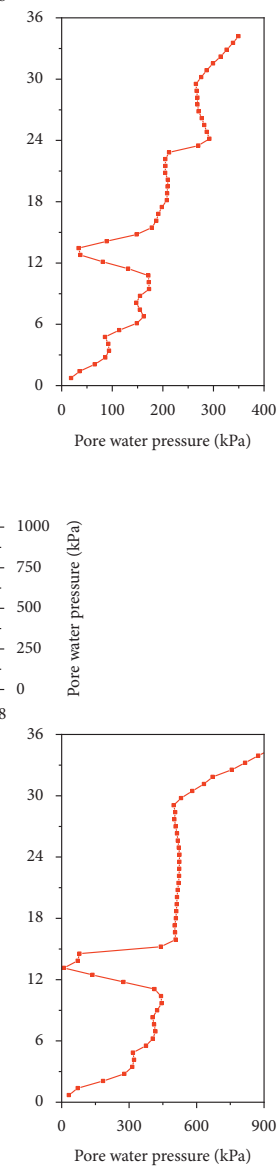

FiguRE 12: Nephogram of pore-water pressure and pore-pressure survey-line data. (a) $0.1 \mathrm{MPa}$ water pressure. (b) $0.4 \mathrm{MPa}$ water pressure. (c) $0.6 \mathrm{MPa}$ water pressure. (d) $1 \mathrm{MPa}$ water pressure.

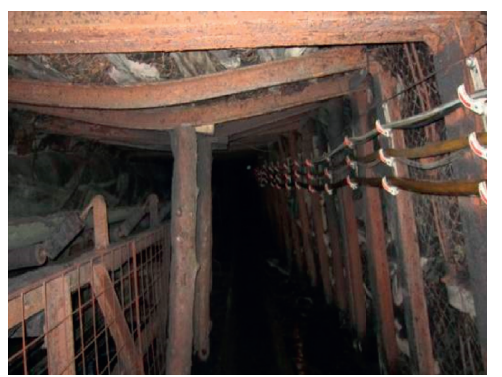

(a)

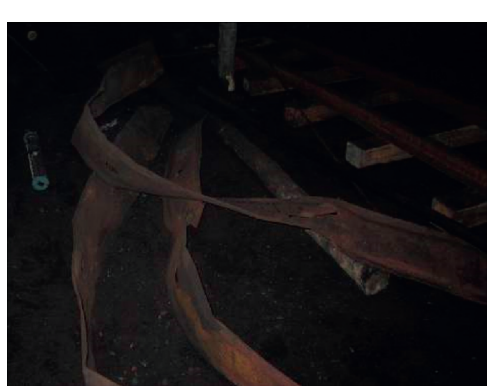

(b)

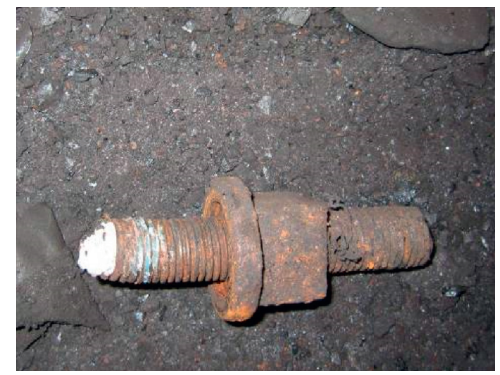

(c)

Figure 13: Current status of roadway support. (a) Roof subsidence. (b) Falling steel band. (c) Broken rock bolt.

redistributed at the initial stage of excavation, with separation and fracture occurring in the surrounding rocks within the range of $1.4 \mathrm{~m}$. Over time, influenced by the overhead water body, reciprocal water-rock interactions caused the appearance of new fracture zones and weak planes in shallow surrounding rocks, leading to separation and gradual propagation of the fractures towards deeper surrounding rocks. Overall, the general stability of the surrounding rocks of the roadway remained adequate. 


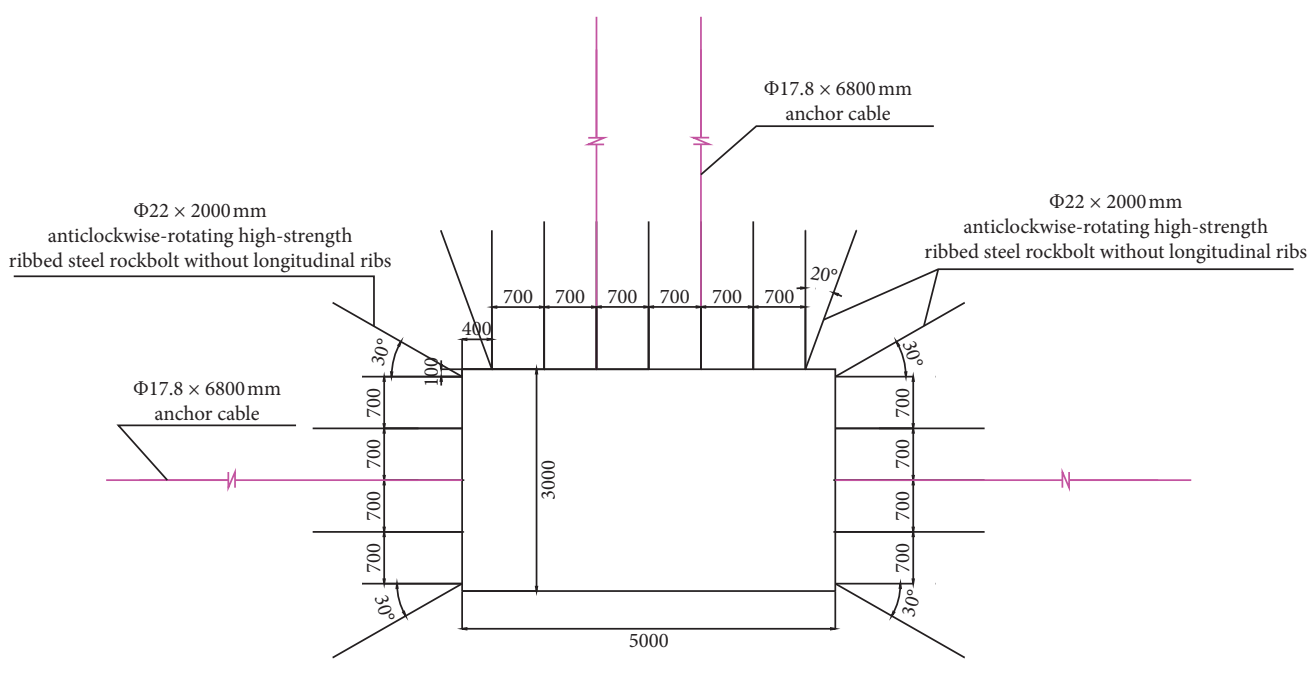

(a)

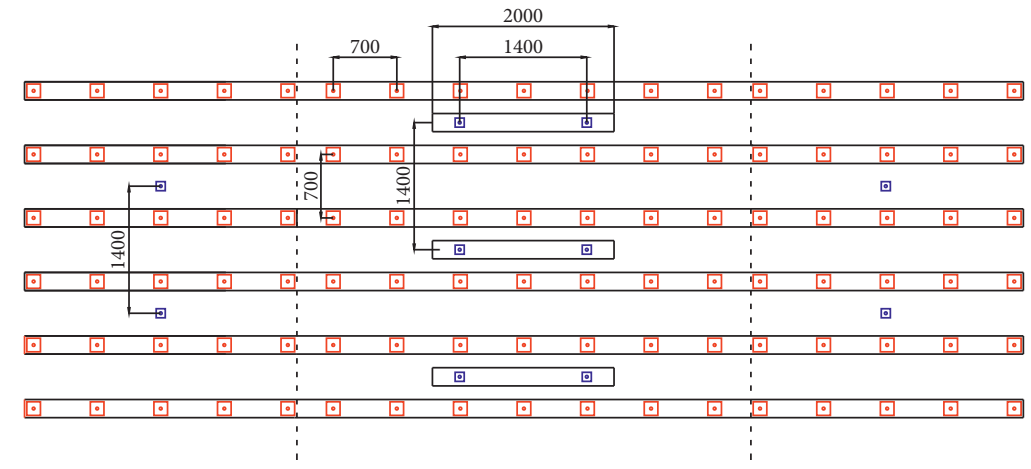

(b)

FIGURE 14: Roadway-support plan. (a) Cross section of support (unit: mm). (b) Expanded view of support (unit: mm).

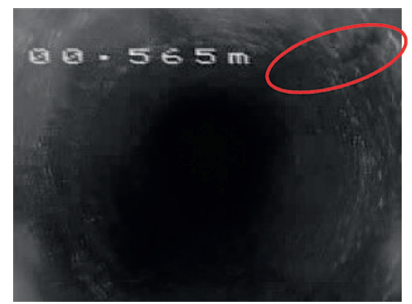

(A) Vertical microfracture

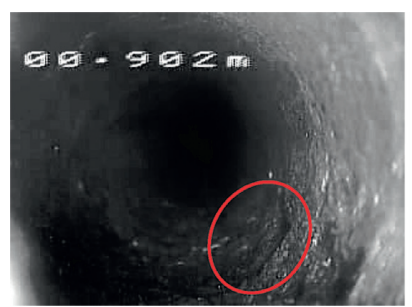

(A) Oblique fracture

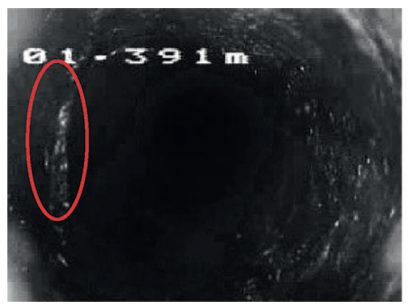

(B) Weak plane

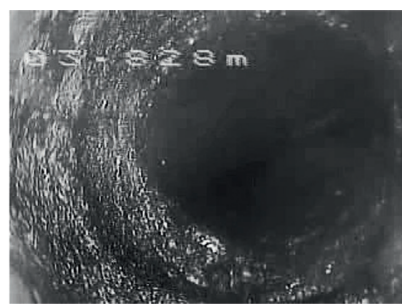

(C) Horizontal fracture

(a)

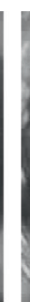

(B) Vertical fracture
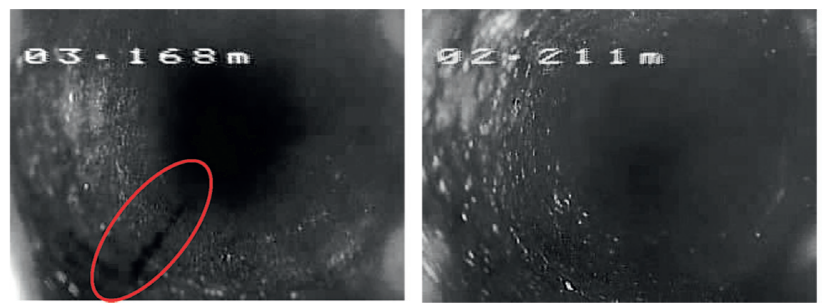

(C) Intact area

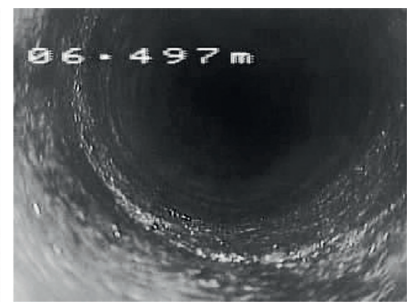

(D) Intact area

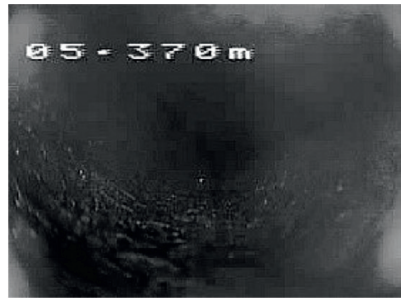

(b)

Figure 15: Continued. 


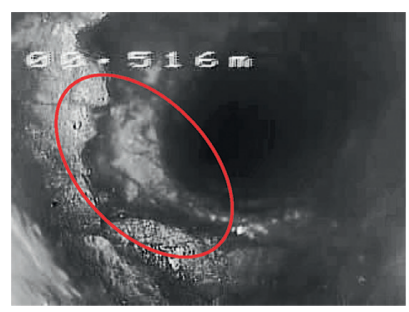

(A) Separated stratum

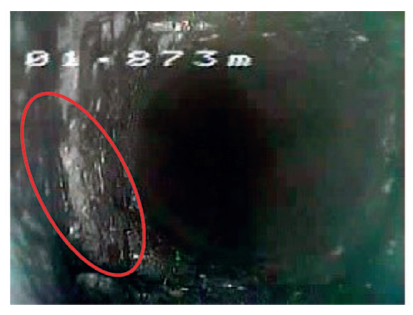

(B) Horizontal fracture

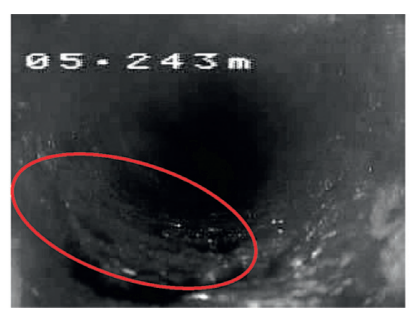

(C) Area with oblique fracture

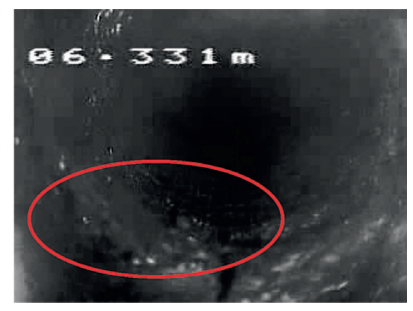

(c)

FIGURE 15: States of strata observed from boreholes at observation stations \#1-3. (a) State of strata observed from borehole at observation station \#1. (b) State of strata observed from borehole at observation station \#2. (c) State of strata observed from borehole at observation station \#3.

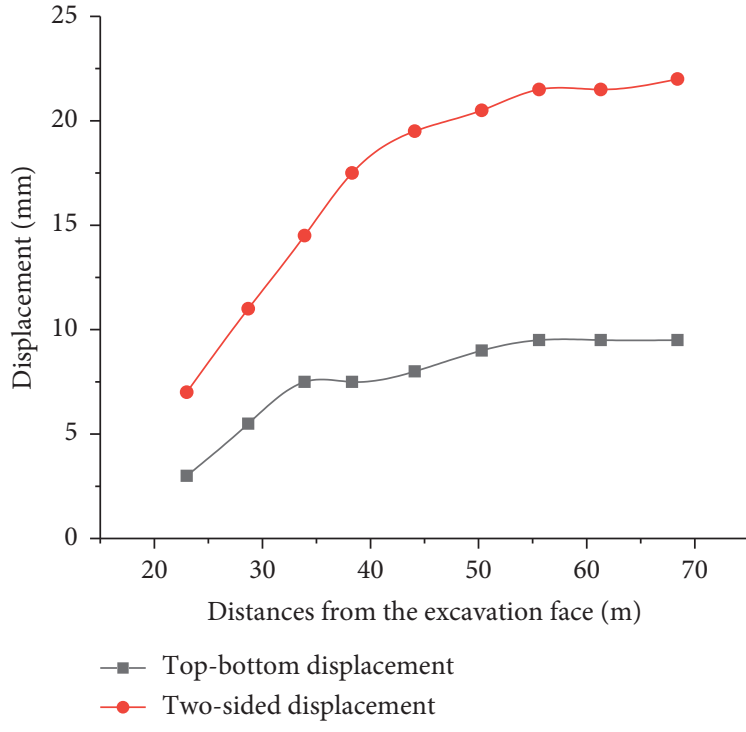

(a)

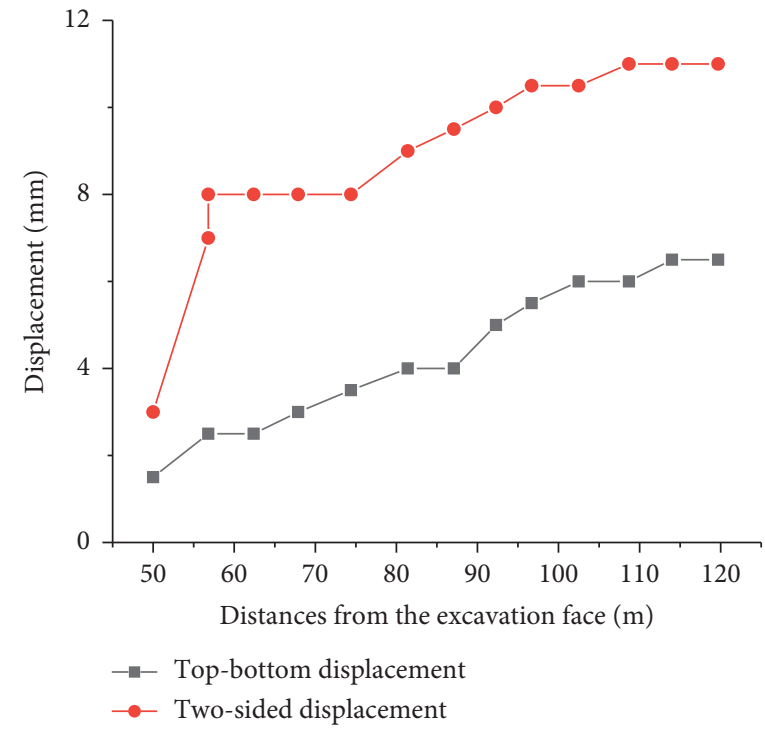

(b)

Figure 16: Roadway surface displacement. (a) $23 \mathrm{~m}$ away from excavation face. (b) $50 \mathrm{~m}$ away from excavation face.

All stations for surface-displacement measurement were located $23 \mathrm{~m}$ and $50 \mathrm{~m}$ away from the excavation face. The curves demonstrating the relationship between the relative distance between two roadway sides and that between the roof and excavation face are depicted in Figure 16. As can be seen, during the initial stages, the roadway deformation is dominated by the roof and floor movements. In contrast, during the later stages, the movement of the two sides dominates the said deformation. After excavation, the roadway becomes stable, and the surrounding rock, too, demonstrates good stability.

\section{Conclusion}

The proposed study investigates the deformation, strength, and pore-structure characteristics as well as surroundingrock control of the mine-roadway sandstone roof subjected to water pressure. This investigation was performed using rock-mechanics testing methods, numerical simulations, and engineering principles. Major conclusions drawn from this study include the following:
(1) The unloading confining pressure ratio was used in combination with the rate of change of strain to categorize the unloading stage as elastic compaction, unloading development, and unloading propagation stages. The residual strain was proportional to the pore pressure. The elastic moduli of the unloading development and propagation stages dropped significantly owing to the pore water pressure.

(2) Shear failure was dominant in the specimen. However, with the increase in pore water pressure, the failure characteristics transformed from a single dominant crack to multiple overlapping cracks, and characteristics of the compressionshear failure manifested. The crack initiation point $\sigma_{c i}$ and volume expansion point $\sigma_{c d}$ were inversely proportional to the pore water pressure. Deformation and failure responses of the specimens to the changes in the confining pressure increased. The time between crack initiation and volume expansion reduced, and the conversion process was hastened. 
(3) The change in the water inflow correlated with the initial microcrack compaction, stable crack growth, and propagation of initiated crack. The water inflow gradually increased with the increase in osmotic pressure, and the volumetric strain required for the realization of maximum water inflow gradually decreased. The variation in water inflow can, thus, be considered a feature to detect specimen-failure occurrence.

(4) As the water pressure increased, the effects of water-rock coupling were strengthened, enhancing the impact on the rocks surrounding the roadway and increasing the area of disturbance. The subsidence of the roadway roof gradually increased, and the separation of the shallow surrounding rocks $(\leq 2 \mathrm{~m})$ was relatively large, with a significant increase in the number of fractures. Fractures in the surrounding rocks of the roadway were mainly formed by joint dislocations and developed toward the top of the roadway to overlap with the open fractures. An area penetrated by fractures was formed in the surrounding rocks of the roadway, causing severe deformation of the roadway.

(5) Combining experimental analysis, numerical simulation, and practical engineering evaluations, a support plan was developed where high-performance rock bolts, cable-bolt reinforcement, and $\mathrm{W}$-shaped steel band protection were selected and applied to ensure stability of the roadway with a sandstone roof under changing water pressure, thereby providing effective protection for safe production in mines.

It is noteworthy that the unloading seepage-flow test was performed to exclusively investigate the specimen deformation and failure at a depth of approximately $300 \mathrm{~m}$ (confining pressure $=4 \mathrm{MPa}$ ). The surrounding rock structure as well as existing faults and other factors were not considered in the numerical simulations. Nonetheless, the results obtained in this study provide a ready reference to control the rocks surrounding miningroadway roofs subjected to reservoir water disturbances. In future studies, the authors intend to consider such factors as the buried depth and goaf to investigate further to control the rocks surrounding the roadway roof under complex mining conditions and reservoir water disturbances.

\section{Data Availability}

The data used to support the findings of this study are available from the corresponding author upon request.

\section{Conflicts of Interest}

The authors declare that they have no conflicts of interest regarding the publication of this paper.

\section{Acknowledgments}

This project was supported by the Joint Funds of the National Natural Science Foundation of China (Grants nos. U1965107 and 51979218).

\section{References}

[1] Y. Teng, D. Gao, W. Zhu et al., Coal Mining Under Water, Coal Industry Press, Beijing, China, 2012.

[2] Y. Kang and B. Shen, Coal Mining Under Water-Macroscopic Classification and Development Strategy, Coal Industry Press, Beijing, China, 2012.

[3] L. Fan, X. Ma, Z. Jiang, K. Sun, and R. Ji, "Review and thirty years prospect of research on water-preserved coal mining," Coal Science and Technology, vol. 47, no. 7, pp. 1-30, 2019.

[4] Y. Sun, Z. Xu, and Q. Dong, "Monito-ring and simulation research on development of waterflow wing fractures for coal mining under Xiaolangdi reservoir," Chinese Journal of Rock Mechanics and Engineering, vol. 28, no. 2, pp. 238-245, 2009.

[5] C. G. Dyke and L. Dobereiner, "Evaluating the strength and deformability of sandstones," Quarterly Journal of Engineering Geology and Hydrogeology, vol. 24, no. 1, pp. 123-134, 1991.

[6] P. S. B. Colback and B. L. Wiid, "The influence of moisture content on the compressive strength of rocks," in Proceedings of the 3rd Canadian Rock Mechanics Symposium, pp. 65-83, Ottawa, Canada, October 1965.

[7] J. Hadizadeh and R. D. Law, "Water-weakening of sandstone and quartzite deformed at various stress and strain rates," International Journal of Rock Mechanics and Mining Sciences \& Geomechanics Abstracts, vol. 28, no. 5, pp. 431-439, 1991.

[8] R. Risnes, H. Haghighi, R. L. Korsnes, and O. Natvik, "Chalkfluid interactions with glycol and brines," Tectonophysics, vol. 370, no. 1-4, pp. 213-226, 2003.

[9] Q. Yao, Researches on Strength Weakening Mechanism and Control of Water-Enriched Roofs of Roadway, China University of Mining and Technology. School of Mining Engineering, Xuzhou, China, 2011.

[10] J. Zhu, J. Deng, Y. Huang, and Z. Yu, "Experimental study on the characteristic strength of saturated marble," Chinese Journal of Rock Mechanics and Engineering, vol. 38, no. 6, pp. 1129-1138, 2019, in Chinese.

[11] Z. Zhu, A. Zhang, and W. Xu, "Experimental research on complete stress-strain process seepage characteristics of brittle rock," Rock and Soil Mechanics, vol. 23, no. 5, pp. 555-559, 2002, in Chinese.

[12] X. Chen and L. Li, "Experimental study of unloading mechanical properties of rock under high confining pressure and high water pressure," Chinese Journal of Rock Mechanics and Engineering, vol. 27, no. Supp. 1, pp. 2694-2699, 2008, in Chinese.

[13] O. Tang, T. Li, and G. Chen, "Experimental study of the effect of moisture content on progressive failure process of sandstone," Journal of Experimental Mechanics, vol. 13, no. 4, pp. 503-510, 2016, in Chinese.

[14] H.-F. Deng, Z. Wang, J.-L. Li, Q. Jiang, and H.-B. Zhang, "Effect of unloading rate and pore water pressure on mechanical properties of sandstone," Chinese Journal of Geotechnical Engineering, vol. 39, no. 11, pp. 1976-1983, 2017, in Chinese.

[15] H. Deng, Z. Wang, J. Li et al., "Experimental research about influence of low pore water pressure on unloading mechanical properties of sandstone," Journal of Rock Mechanics and 
Engineering, vol. 36, no. Supp. 1, pp. 3266-3275, 2017, in Chinese.

[16] J. Xu, H. Yang, S. Peng, Y. Jiang, and Y. Zhang, "Experimental study of mechanical property of sandstone under pore water pressure and confining pressure," Chinese Journal of Rock Mechanics and Engineering, vol. 29, no. 8, pp. 1618-1623, 2010, in Chinese.

[17] R. Wang, B. Xu, W. Xu, W. Wang, Z. Lin, and J. Zhang, "Experimental study on influence of different unloading paths on permeability evolution of sandstone," Journal of Rock Mechanics and Engineering, vol. 38, no. 3, pp. 467-475, 2019, in Chinese.

[18] X. Wang, G. Rong, and C. Zhou, "Permeability experimental study of gritstone in deformation and failure processes," Chinese Journal of Rock Mechanics and Engineering, vol. 31, no. Supp. 1, pp. 2940-2947, 2012, in Chinese.

[19] W. Zhu and Y. Teng, "Study on the safety and mining influence of fully-mechanized caving mining with ultra-thick seam under barrier lake," Journal of Mining and Strata Control Engineering, vol. 3, no. 1, Article ID 013525, 2021.

[20] B. Liu, Y. Ma, H. Sheng, H. Deng, Q. Han, and Y. Cao, "Experimental study on mechanical properties of cretaceous red sandstone under the freezing temperatures and confining pressures," Chinese Journal of Rock Mechanics and Engineering, vol. 38, no. 3, pp. 455-466, 2019, in Chinese.

[21] D. Lu, X. Du, and C. Xu, "Analytical solutions to principle of effective stress," Chinese Journal of Geotechnical Engineering, vol. 35, no. Supp. 1, pp. 146-151, 2013, in Chinese.

[22] K.-P. Zhou, Z.-X. Hu, F. Gao, M.-Q. Wang, and Z. Yang, "Study of marble damage evolution laws under unloading conditions based on nuclear magnetic resonance technique," Chinese Journal of Rock Mechanics and Engineering, vol. 33, no. Supp. 2, pp. 3523-3530, 2014, in Chinese.

[23] M. Cai, P. K. Kaiser, Y. Tasaka, T. Maejima, H. Morioka, and M. Minami, "Generalized crack initiation and crack damage stress thresholds of brittle rock masses near underground excavations," International Journal of Rock Mechanics and Mining Sciences, vol. 41, no. 5, pp. 833-847, 2004.

[24] Z. T. Bieniawski, "Mechanism of brittle fracture of rock," International Journal of Rock Mechanics and Mining Sciences \& Geomechanics Abstracts, vol. 4, no. 4, pp. 407-423, 1967.

[25] Itasca Consulting Group Inc, UDEC (Universal Distinct Element Code) User's Manual, Itasca Consulting Group. Inc., Minneapolis, MN, USA, 2014.

[26] S. Pelliza and D. Peila, "Soil and rock reinforcements in tunneling," Tunneling and Underground Space Technology, vol. 8, no. 3, pp. 223-233, 1993. 